13

\title{
Полевая десорбция цезия с рения
}

\author{
() Д.П. Бернацкий, В.Г. Павлов
}

Физико-технический институт им. А.Ф. Иофффе РАН, Санкт-Петербург, Россия

E-mail: bernatskii@ms.ioffe.ru

Поступило в Редакцию 31 мая 2017 г.

С помощью метода полевой десорбционной микроскопии исследована десорбция атомов цезия с рениевого полевого эмиттера в электрическом поле. Получена зависимость напряженности десорбирующего электрического поля от степени покрытия поверхности эмиттера атомами цезия. В рамках модели сил зеркального изображения для полевой десорбции проведена оценка теплоты адсорбции атомов цезия в зависимости от поверхностной концентрации цезия и работы выхода поверхности. Науглероживание рениевого эмиттера приводит к изменению характера десорбции и распределения зон десорбции по поверхности эмиттера.

DOI: 10.21883/PJTF.2018.04.45645.16893

Изучение явления полевой десорбции - важная научная задача, поскольку ионные источники, работающие на этом принципе, представляют большой интерес для применения в ионно-лучевых технологиях [1,2]. В настоящей работе исследована десорбция цезия с рениевого полевого эмиттера в электрическом поле при температуре эмиттера $T=300 \mathrm{~K}$. Задачей работы являлось изучение зависимости величины напряженности десорбирующего поля от степени покрытия эмиттера цезием, а также визуализация процессов десорбции и изучение влияния науглероживания эмиттера на процессы десорбции цезия. Для проведения исследований использовался полевой десорбционный микроскоп с широкоугольным атомным зондом [3].

Одним из важных параметров в исследовании полевой десорбции является определение напряженности десорбирующего электрического поля, которая зависит, в частности, от потенциала ионизации и теплоты адсорбции атомов адсорбата, работы выхода поверхности, материала эмиттера. Существенным фактором служит распределение 
ионного тока по поверхности эмиттера, позволяющее определять области эмиссии, что имеет немаловажное значение для фокусировки ионного пучка. Использование полевого десорбционного микроскопа с широкоугольным атомным зондом помимо определения перечисленных выше параметров позволяет визуализировать изображение поверхности в десорбируемых ионах в нанометровом масштабе, а также проводить оценку масс десорбирующихся ионов. В используемом полевом десорбционном микроскопе применена система регистрации, состоящая из двух микроканальных пластин диаметром $56 \mathrm{~mm}$ и люминесцентного экрана, которые отстоят от полевого эмиттера на расстояние порядка $10 \mathrm{~cm}$. Прикладывание к эмиттеру импульсов напряжения длительностью 2-10 ns и амплитудой 2-5 kV одновременно с постоянным напряжением делает возможными измерение времени пролета ионов от эмиттера до регистрирующей системы, запись времяпролетных масс-спектров и проведение оценки масс десорбирующихся ионов.

В неоднородном электрическом поле можно создать условия для диффузии атомов цезия (щелочных металлов) по поверхности полевого эмиттера от периферии к центру. Поверхность вершины эмиттера, сформированная с помощью отжига, представляет собой близкую к полусфере поверхность монокристалла равновесной формы с расположенными на ней плоскими низкоиндексными гранями. Атомы цезия на поверхности эмиттера десорбируются приложенным электрическим полем с мест, где выполняются условия для полевой десорбции. Десорбирующиеся ионы создают на экране полевого эмиссионного микроскопа десорбционные изображения. Наблюдая за динамикой полевых десорбционных изображений, можно изучать влияние различных факторов на процессы десорбции и подбирать оптимальные режимы работы источника.

Полевой эмиттер для исследований изготавливался из рениевой проволоки путем электрохимического травления в кислотном растворе. Затем в камере полевого эмиссионного микроскопа производился отжиг эмиттера в высоком вакууме $\left(P<10^{-9}\right.$ Torr $)$ при температуре $T=2500 \mathrm{~K}$. Во время отжига происходила очистка рения и формирование кристаллической структуры эмиттера в виде острия с радиусом вершины порядка $500 \mathrm{~nm}$. Процессы очистки и формирование острия формы отжига контролировались по полевым электронным изображениям поверхности. После формирования полевого

Письма в ЖТФ, 2018, том 44, вып. 4 


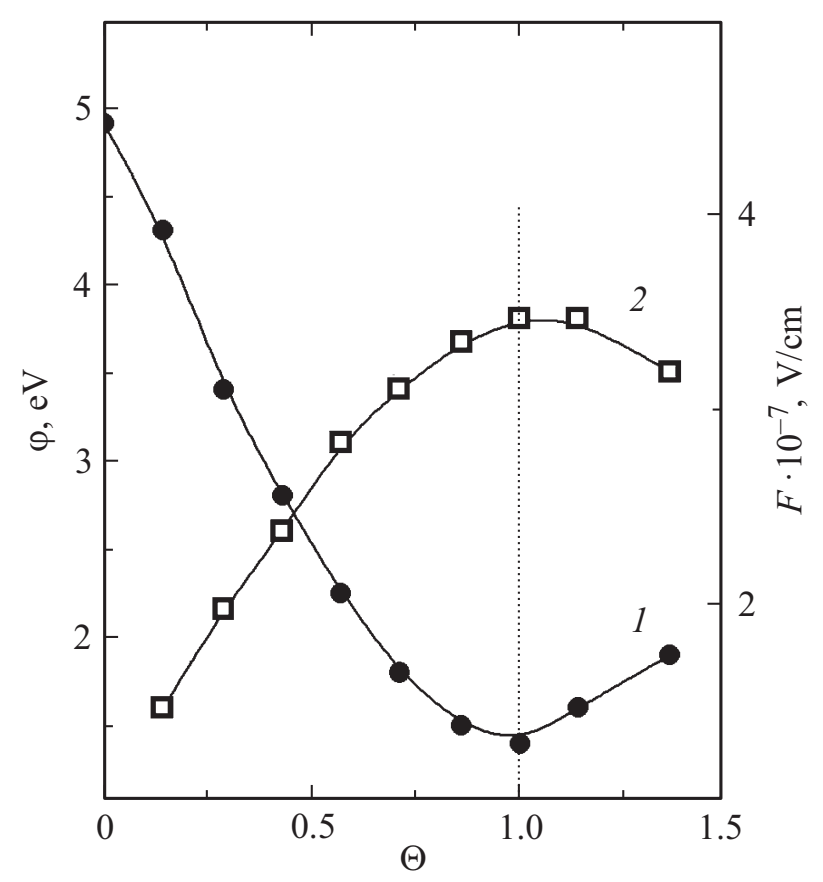

Рис. 1. Зависимость работы выхода (1) и напряженности десорбирующего электрического поля (2) от степени покрытия атомами цезия рениевого полевого эмиттера.

эмиттера наблюдалось стандартное полевое электронное изображение сферической поверхности кристалла рения с центральной гранью (112̄0) [4].

Работа выхода поверхности эмиттера и напряженность электрического поля измерялись с использованием вольт-амперных характеристик полевой электронной эмиссии (характеристик Фаулера-Нордгейма).

На рис. 1 приведены экспериментальные зависимости работы выхода поверхности эмиттера и напряженности десорбирующего электрического поля от степени покрытия $\Theta$ эмиттера цезием. За степень покрытия, равную $\Theta=1$, принято покрытие, при котором наблю-

Письма в ЖТФ, 2018, том 44, вып. 4 
Энергии активации десорбции атома $(\Lambda)$ и иона $\left(Q_{0}\right)$ Cs в отсутствие электрического поля в зависимости от степени покрытия $(\Theta)$ поверхности рения цезием

\begin{tabular}{c|c|c|c|c|c|c|c|c}
\hline & \multicolumn{10}{|c}{$\Theta$} \\
\cline { 2 - 9 }$\Delta, \mathrm{eV}$ & 0 & 0.14 & 0.29 & 0.43 & 0.57 & 0.71 & 0.86 & 1 \\
$Q_{0}, \mathrm{eV}$ & 1.9 & 2.5 & 2.3 & 1.9 & 1.5 & 1.1 & 0.9 & 0.9 \\
2.1 & 2.8 & 3 & 3.1 & 3.2 & 3.3 & 3.4
\end{tabular}

дается минимальное значение работы выхода поверхности эмиттера. Величина напряженности десорбирующего электрического поля $F$ растет с увеличением степени покрытия атомами цезия поверхности рениевого полевого эмиттера и достигает максимального значения в области покрытия $\Theta=1$. В области покрытий эмиттера цезием $\Theta$ от 0 до 1 полевая десорбция носила лавинообразный характер, и атомы цезия десорбировались со всей вершины эмиттера, что регистрировалось по полевым электронным и десорбционным изображениям поверхности эмиттера. При $\Theta_{1}=\Theta>1$ полевая десорбция имела сложный характер. При повышении напряженности поля происходила частичная десорбция атомов цезия, и степень покрытия уменьшалась до значения $\Theta_{2}\left(1<\Theta_{2}<\Theta_{1}\right)$, десорбция прекращалась. При дальнейшем увеличении напряженности поля происходила десорбция одиночных атомов цезия, покрытие эмиттера цезием постепенно уменьшалось, и когда оно достигало значения, равного единице, наблюдалась лавинообразная десорбция всего оставшегося цезия.

Для описания процессов полевой десорбции атомов щелочных металлов, обладающих малыми потенциалами ионизации, может быть использована модель сил зеркального изображения [5], согласно которой максимум потенциальной энергии иона в электрическом поле понижается в соответствии с эффектом Шоттки. Энергия активации для полевой десорбции однократно заряженного иона может быть представлена в виде $Q=Q_{0}-e^{3 / 2} F^{1 / 2}$, где $Q_{0}$ - энергия десорбции иона в отсутствие электрического поля, $e-$ заряд электрона, $F-$ напряженность приложенного электрического поля. Энергия десорбции

Письма в ЖТФ, 2018, том 44, вып. 4 

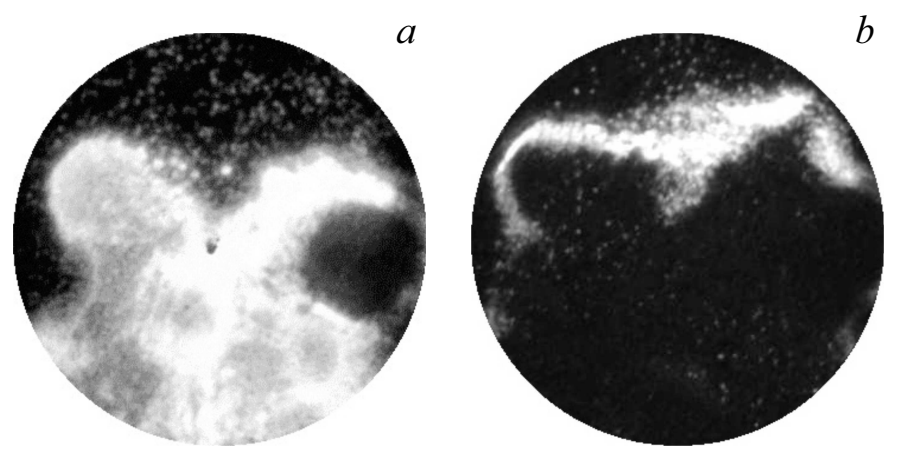

Рис. 2. Полевые десорбционные изображения рений-цезий.

иона $Q_{0}$ в отсутствие электрического поля связана с энергией десорбции нейтрального атома $\Lambda$ выражением $Q_{0}=\Lambda(\Theta)+I-\phi(\Theta)$, где $I-$ потенциал ионизации атома, $\varphi-$ работа выхода поверхности. С использованием этой модели полевой десорбции на основе полученных экспериментальных данных была проведена оценка энергии десорбции атома цезия и энергии десорбции иона с поверхности рениевого эмиттера (см. таблицу).

При оценке теплоты десорбции энергию активации десорбции в десорбирующем электрическом поле при температуре $T=300 \mathrm{~K}$ принимали равной нулю. Энергия десорбции иона $Q_{0}$ увеличивается с ростом покрытия поверхности эмиттера атомами цезия. Это связано с тем, что работа выхода поверхности уменьшается быстрее, чем энергия десорбции нейтрального атома $\Lambda$. Тогда в области покрытий $\Theta<1$ при десорбции атомов цезия с уменьшением степени покрытия происходит уменьшение энергии десорбции иона $Q_{0}$. Скорость полевой десорбции для термически активируемого процесса, определяемая уравнением Аррениуса, при этом увеличивается. Это приводит к лавинообразной десорбции, что и наблюдается в эксперименте. Похожие зависимости наблюдались при полевой десорбции щелочных металлов с вольфрама [6].

На рис. 2 приведены полевые десорбционные изображения полевого эмиттера, которые отражают распределение ионного тока по поверхности эмиттера в процессе десорбции. На рис. 2, $a$ показан

Письма в ЖТФ, 2018, том 44, вып. 4 


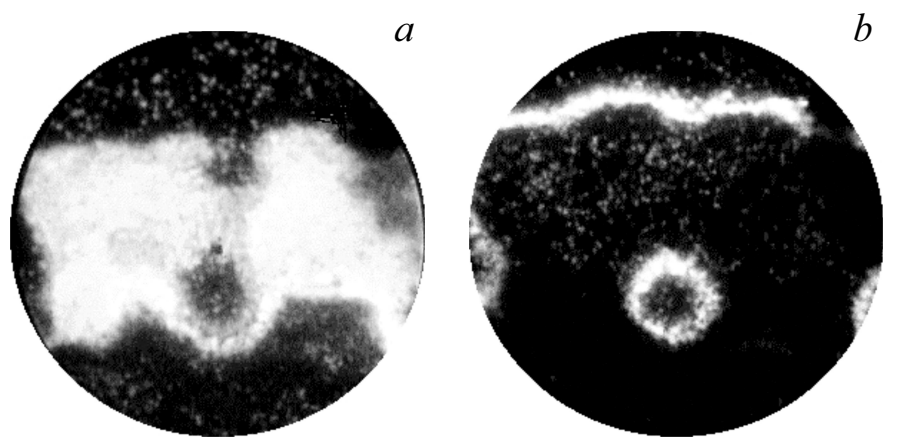

Рис. 3. Полевые десорбционные изображения рений-углерод-цезий.

момент лавинообразной вспышки ионов цезия со всей вершины полевого эмиттера при достижении десорбирующего напряжения. После вспышки остается фронт десорбции (рис. 2,b). Фронт десорбции обусловлен диффузией адатомов цезия по поверхности эмиттера в неоднородном электрическом поле с боковой поверхности на вершину. Локальное местоположение фронта десорбции определяется приложенным электрическим напряжением и локальным усилением электрического поля, т.е. находится там, где на поверхности достигается пороговое для десорбции значение напряженности поля. В области от фронта до периферии эмиттера поверхность покрыта цезием, напряженность электрического поля меньше порогового значения для этого покрытия и десорбция отсутствует, а после фронта (в центре эмиттера) атомы цезия уже десорбировались ранее. При повышении приложенного напряжения фронт десорбции смещается к периферии, а при понижении - к центру наблюдаемого изображения вследствие притока адатомов цезия с боковой поверхности эмиттера.

Мы провели науглероживание рениевого эмиттера с помощью бензола по методике [7] и обнаружили появление эмиссии ионов цезия в центре эмиттера после лавинообразной десорбции со всей вершины, что не свойственно чисто металлическим системам. Такой характер десорбции может быть связан с тем, что не все атомы цезия, нанесенные на поверхность эмиттера, десорбируются во время

Письма в ЖТФ, 2018, том 44, вып. 4 
лавинообразной вспышки. Мы полагаем, что некоторая часть атомов цезия во время напыления на поверхность эмиттера, накапливается в интеркалированном состоянии в углеродных наноструктурах [8]. Эти углеродные наноструктуры могут образовываться на поверхности рения в нагретом состоянии при наличии углеводородов. При увеличении напряжения сначала происходит лавинообразная десорбция цезия с вершины эмиттера (рис. 3,a). При дальнейшем увеличении напряжения (рис. $3, b$ ) наблюдается фронт десорбции атомов цезия с поверхности, а также десорбция в области центральной грани (112̄0) рениевого полевого эмиттера. Изменение приложенного напряжения меняет только расположение фронта десорбции, поскольку влияет на достижение порогового значения электрического поля в различных местах на поверхности эмиттера. Поэтому увеличение электрического поля приводит к движению фронта десорбции от центра эмиттера к периферии, в то время как на десорбцию с углеродных наноструктур, окружающих плоскую грань (112̄0), оно практически не оказывает влияния.

Таким образом, полевая десорбция цезия с чистого рения качественно аналогична десорбции с других тугоплавких металлов. Особенности рения связаны с взаимодействием молекул углеводородов, выделением атомов углерода на поверхность и значительной растворимостью углерода в объеме металла. Эти особенности влияют на процесс полевой десорбции и могут сказаться на характеристиках ионных источников.

\section{Список литературы}

[1] Nanofabrication using focused ion and electron. Principles and applications / Eds I. Utke, S. Moshkalev, P. Russell. Oxford University Press, 2012. 380 p.

[2] Avasthi D.K., Mehta G.K. Swift heavy ions for materials engineering and nanostructuring. Springer Ser. in Materials Science. 2011. V. 145. 280 p.

[3] Бернацкий Д.П., Павлов В.Г. // Изв. РАН. Сер. физ. 2009. Т. 73. № 5. С. $713-$ 715.

[4] Beach Th., Vanselow R. // Appl. Phys. 1974. V. 4. P. 265-270.

[5] Muller E.W., Tsong T.T. Field ion microscopy, field ionization and field evaporation. Pergamon Press, 1973. P. 81.

Письма в ЖТФ, 2018, том 44, вып. 4 
[6] Bernatskii D.P., Pavlov V.G. // Phys. Low-Dim. Struct. 1997. V. 7. P. 93-98.

[7] Rut'kov E.V., Gall N.R. // Physics and applications of graphene - experiments / Ed. S. Mikhailov. InTech, 2011. P. 209-292.

[8] Бернацкий Д.П., Павлов В.Г. // Письма в ЖТФ. 2016. Т. 42. В. 11. С. 105-110. 